\title{
Parodia como estrategia post-genealógica: una lectura del feminismo de Judith Butler desde la filosofía de M. Foucault
}

\author{
Carlos PÉREZ HERRANZ \\ Universidad Complutense de Madrid \\ cpherranz@gmail.com
}

Recibido: 05.03.2013

Aceptado: 15.11.2013

\section{RESUMEN}

Frente a las corrientes feministas claramente encuadradas en una teoría política de la igualdad o de la diferencia, la irrupción de Judith Butler en el espacio teórico del feminismo constituye, a mi modo de ver, un giro revolucionario en la historia de esta disciplina. Este carácter viene dado, principalmente, por la operación que efectúa respecto al sujeto-objeto de estudio de esta rama teórica. En este ensayo vamos a relacionar esta revolución con la asunción del método genealógico de análisis de la historia defendido por Foucault, cuya aplicación en una "arqueología del feminismo" daría lugar a nuevas estrategias políticas de resistencia ante la amenaza logofalocéntrica.

Palabras clave: genealogía, genética, materia, performatividad, parodia.

Parody as a post-genealogical strategy: reading Judith Butler's feminism through the lens of the philosophy of M. Foucault

\begin{abstract}
Versus the currents of feminists clearly framed by a political theory of equality or of difference, the emergence of Judith Butler in the field of feminist theory constitutes, in my view, a complete revolution in the history of the discipline. This quality is derived, principally, from the turn she makes_with regard to the subject-object of study in this branch of theory. In this essay I will link this revolution to the genealogical method of analysis defended by Foucault, whose application in the "archeology of feminism" will lay the groundwork for new strategies for political change and resistance against the perpetual threat of phallocentric logic.
\end{abstract}

Key words: genealogy, genetic, matter, performativity, parody.

\section{INTRODUCCIÓN}

Tradicionalmente se ha entendido que existe un sujeto histórico femenino cuya identidad se preservaba a lo largo de los siglos y las épocas gracias a su sexo, género y sexualidad propias. Estos tres conceptos estabilizaban la noción de "mujer" que constituía el objeto de la reflexión feminista. Una determinada morfología corporal, así como unas determinadas atribuciones culturales o prácticas ligadas a una 
condición social, y unos modos específicos de procurarse placer, estrechamente unidos a la funcionalidad de su anatomía y a las reglas morales de turno, eran los tres rasgos a partir de los cuales el feminismo podía determinar su objeto de estudio. El análisis histórico guiado por estos tres "puntos cardinales" permitía localizar a la mujer a través de las diferentes etapas de la historia universal (e incluso encontrar esa figura perfectamente distinguible en las comunidades prehistóricas), tomándola (de la misma manera que al hombre) como un objeto presente en la realidad de cada una de las épocas estudiadas. La mujer era, por tanto, una cosa, una realidad antropológica constante: la mitad del par hombre/mujer que definía el binarismo tanto genérico como sexual en el que se movía la especie humana. Esta perspectiva partía de un razonamiento-justificación de este tipo:

El ser humano es un animal y, como en cualquier otra especie, la satisfacción de su "necesidad" reproductiva está sujeta a un sistema de división sexual muy concreto: para la creación de nuevos individuos humanos es preciso el acoplamiento de dos sistemas reproductores anatómicamente definidos y diferenciados. Sólo por medio del encuentro de los dos cuerpos (guardianes de capacidades diferentes, irreductibles la una a la otra y, desde este punto de vista reproductivo, complementarias) puede engendrarse un nuevo individuo (cuyo sexo será también definido según sus potencialidades reproductivas, claramente significadas por una u otra anatomía). Gracias a esta diferencia física podemos distinguir dos "tipos" de seres humanos: el macho y la hembra, el hombre y la mujer. En virtud y a partir de esta diferencia natural, los cuerpos femeninos ya cargan con una función social: por ser el vehículo de la venida al mundo del nuevo individuo, y la condición sine qua non de la supervivencia de la especie, estos cuerpos son portadores de un valor específico y han de ser introducidos cuidadosamente en un régimen económico que haga con ellos el mejor de los usos posibles según los intereses de la comunidad. ${ }^{1}$

Nos encontramos con la descripción de un objeto que se hace presente en el campo de la historia a partir de las notas de sexo (como forma que dota de contorno y cualidad a la mera carne, como figura que delimita las fronteras corpóreas y capacidades físicas del individuo) y de género (como "especificidad cultural", como aquellos "movimientos" o acciones que le son propios a la materia sexuada). Pues bien, ese objeto, esa "constante-mujer", ha ocupado tradicionalmente una posición de subordinación ante una autoridad que ha dictado las reglas de la economía de los cuerpos (aquella por la que se cualificaban socialmente los cuerpos femeninos y que

\footnotetext{
${ }^{1}$ Cierto es que los cuerpos masculinos también se hallan cualificados socialmente en virtud de sus potencialidades, igualmente necesarias para la reproducción e insustituibles por las de los cuerpos femeninos, pero la relación de poder instaurada socio-políticamente ha tenido tradicionalmente, y por las razones que sean, a los cuerpos femeninos lejos de la posición dominante ocupada por los cuerpos masculinos.
} 
permitía que las mujeres fuesen utilizadas (ya en la época prehistórica) como simples vientres parideros susceptibles de ser puestos a disposición de los intereses estratégicos de los detentores del poder en operaciones de alianza con otras tribus vecinas) y que, coartando su libertad, le ha impuesto un estricto código de normas y categorías a respetar para poder seguir siendo parte de la sociedad. Ante esta situación, la historia feminista se revuelve contra la historia de la humanidad, denunciando la contingencia de la cuestión genérica: la asunción de unos "movimientos propios", de unas categorías de pensamiento ajenas que atentan contra el libre discurrir de las mujeres, de toda una serie de funciones sociales y normas de comportamiento que "mecanizan" a ese género,... no es necesaria. Si el cuerpo de las mujeres puede comportarse como el de los hombres en tantos aspectos, ¿por qué habría de mantenerse encorsetado en una serie de protocolos limitadores? Hay que luchar contra el condicionamiento genérico, pues las mujeres, en tanto que seres humanos, tienen que gozar de la misma libertad de acción que los hombres (postura feminista igualitarista), e incluso, en tanto que cuerpos capaces de hacer cosas con las que los hombres sólo pueden fantasear, hacer valer su diferencia esencial respecto de los hombres, y evidenciar que la instancia de poder puede ser ocupada perfectamente por las mujeres (sin por ello tener que pasar a ser "hombres"; esta es, en unos algo groseros trazos, la postura que aboga por la diferencia). Hay, en cualquier caso, para el feminismo tradicional (pre-Butler), que denunciar todo signo de falocracia, de logofalocentrismo (régimen en el que el sentido parte de la instancia masculina dominante para derramarse sobre toda la sociedad binaria), como un momento de peligro para las bio-mujeres (cuerpo femenino de nacimiento, con o sin aceptación de las reglas del ser-mujer en tanto pertenencia a un género) por denotar una sospechosa dependencia del llamado patriarcado (codificación, cualificación y valoración de lo real en torno a las reglas del ser-hombre que se define por oposición al ser-mujer), que posibilita un estado de tutela permanente que no permite a la mujer salir de su "minoría de edad autoculpable".

Pues bien, Butler, consciente de lo acuciante que resulta el imprimirle una dirección a la acción política feminista (aquella que corte con esta injusta dinámica de sometimiento), propone replantear la acción, que ha sido tradicionalmente entendida desde este marco que no problematiza el binarismo sexual. ¿En qué consiste ser una mujer en tanto sujeto del feminismo? ¿comparten las "mujeres" algún elemento aglutinador que sea realmente anterior a su opresión, o bien comparten un vínculo únicamente como resultado de su opresión? ¿existe una especificidad cultural femenina que no dependa de su subordinación por parte de las culturas masculinistas hegemónicas? (Butler, 2007: 50)

Judith Butler va a revolucionar el feminismo desde el mismo momento en que aborde la cuestión de su objeto (el sujeto femenino) desde una perspectiva genealógica, desde el instante en que deseche toda noción genética de "positividad 
histórica" y preste atención a lo que acontece en la historia. Sólo así obtendrá la clave para la acción política más radicalmente feminista.

“(..) una de las formas de asegurar de manera efectiva la estabilidad interna y el marco binario del sexo es situar la dualidad del sexo en un campo prediscursivo. Esta producción del sexo como lo prediscursivo debe entenderse como el resultado del aparato de construcción cultural nombrado por el género". (Ibid.: 56)

La historicidad del género parece hacerse evidente en el curso de una investigación en la que se toma como objeto el devenir de los cuerpos-mujer a lo largo de los siglos, en el marco de una misma cultura o sociedad. Podemos, simplemente con ojear los archivos, extraer que las condiciones de posibilidad del "ser mujer" como "jugar el rol social de la mujer", han experimentado cambios que han conllevado una redefinición constante del término. Por ejemplo, en la sociedad española de 1900, una mujer era un individuo en cuya definición no entraba la capacidad de entrar "de derecho" en el juego político. El no poder elegir a sus representantes en las cortes era una característica definitoria de la femineidad: eran los cuerpos de los hombres, distinguibles a simple vista por su diferencia anatómica constitutiva, los que podían entrar en el juego electoral. Los hombres elegirían a los que habrían de gobernarles tanto a ellos como a las mujeres de su sociedad, las cuales caerían bajo el dominio de la decisión masculina sin siquiera la posibilidad de pronunciarse sobre quién preferirían que les gobernase.

Si con un ligero salto temporal nos trasladamos a la España de nuestros días, nos encontraremos con que esos mismos cuerpos a los que les estaba prohibida la participación en todo tipo de comicios, se disponen hacia las urnas cada cuatro años (aquellos que lo desean, claro está). Son efectivamente los mismos cuerpos, las mismas plantillas anatómicas antes segregadas y ahora convergiendo con las de los hombres. ¿Qué es lo que ha cambiado? Evidentemente, nada relacionado con el sexo (pues el objeto físico sobre el que posamos nuestra mirada en 1900 es, estructuralmente, el mismo que observamos 110 años después), sino más bien algo relativo a las atribuciones genéricas ligadas a todo cuerpo sexuado desde la matriz binaria. El género es flexible, por tanto: acepta una cierta performatividad, "evoluciona" a medida que se tensa-destensa la cuerda sujeta a sus extremos por la sociedad y la ley o instituciones que han de definir el género con sus políticas, tanto directa como indirectamente. Si el género es aquel conjunto de acciones que "le son propias" a los sexos, y los sujetos son capaces de disponer a voluntad de sus cuerpos según los fines que deseen y que su materialidad les permita, la esencialidad del género queda en entredicho. Teniendo en cuenta esto, podemos entender la división sexual en dos tipos de cuerpo según una motivación económico-política ya presente en las sociedades más arcaicas, pero que a esta dualidad le corresponda un binarismo genérico es algo que no resulta en absoluto evidente. Aun aceptando que hubiese dos 
géneros (como habría dos sexos), la correspondencia entre un cuerpo de bio-mujer y un género femenino no muestra un vínculo necesario. La exclusión de todos aquellos individuos que hayan osado confundir un determinado sexo con su género contrario o viceversa constituye otro argumento o prueba más para ilustrar la contingencia de la determinación genérica.

El género es, por tanto, la estilización repetida del cuerpo, una sucesión de acciones repetidas -dentro de un marco regulador muy estricto- que sedimenta con el tiempo, creando la apariencia de sustancia, de una forma natural de ser (Ibid.: 98). De manera que la esencialidad del género, su naturalidad y su relación de inseparabilidad respecto de cierta forma corporal o sexo, se nos muestra (a la tenue luz de una investigación histórico-genética) como una ficción reguladora propia de una ordenación socio-cultural determinada. ¿Qué hallazgos, qué rigurosos desmontajes ideológicos podrán realizarse apartándose de los objetos constituidos para centrar la mirada en los espacios invisibles que ocupan sus relaciones -aplicando, por tanto, el riguroso método arqueológico ${ }^{2}$ ?

\section{FOUCAULT Y LA GENEALOGÍA: HACIA UNA ONTOLOGÍA MATERIALISTA}

La genealogía aplicada a la investigación histórica es, según el historiador francés Paul Veyne, la fórmula metodológica que convierte a Michel Foucault en un auténtico revolucionario de este campo de conocimiento. ${ }^{3}$

El término "genealogía" era el utilizado por Nietzsche para hablar de su investigación sobre el origen moral de los valores, sobre la naturaleza contingente de la necesidad moral. Este mismo término es recogido por Foucault para afrontar el estudio de "los hechos humanos": se entiende que los hechos históricos, que se articulan en proposiciones pretendidamente objetivas (que dicen algo de algo, que establecen un vínculo necesario entre palabras y cosas), hablan de objetos naturales (por ejemplo "las mujeres" o el sexo femenino encarnado en los cuerpos) que preexisten a cualquier acercamiento teórico. Los hechos naturales, los objetos de la

\footnotetext{
${ }^{2}$ La cuestión de la investigación genealógica es, en Foucault, abordada desde lo que él llama "método arqueológico". Este método, que encuentra positividades históricas diferentes de las de la investigación genética, es el que me dispongo a describir en el siguiente apartado. Por razones de comodidad, el término más utilizado es el de "genealogía", pero tomado en todo momento como “investigación crítica que procede mediante el método arqueológico”. Así, cada vez que se hable de un "método genealógico" se estará haciendo referencia a esta arqueología que proporciona los materiales de estudio a la investigación sobre el origen moral de los conceptos (la genealogía).

3 Véase "Foucault revoluciona la historia" (Veyne, 1980)
} 
historia, son la materia con la que trabaja el historiador. Esta es precisamente la visión que viene a desterrar Foucault con su irrupción revolucionaria.

Según Foucault, hay que apartar la vista de los objetos naturales para observar cierta práctica que los ha objetivado. A la base de lo que aparece objetivado, de los hechos históricos, se encuentra todo un entramado de prácticas constitutivas que han operado sobre lo real para dar lugar a "lo natural". Pero la naturalidad de los objetos o de los hechos pasa, así, a convertirse en una artificialidad. No hay hechos sino para las teorías que los alumbran con su gramática, sus términos y sus categorías. Cada teoría pone en juego un particular "régimen de visibilidad" fuera del cual la cosa resulta "invisible" (por ejemplo, la locura en la época clásica, tema tratado por Foucault, ¿a qué luz puede ser vista? ¿en qué enunciados puede ser dicha? (Díaz Marsá, 1996: 140) Justamente a la que despide todo el edificio del saber inherente a su época, pues todo acercamiento a la realidad de la locura pre-moderna desde una mentalidad moderna no nos devolverá el objeto específico puesto en juego en la época clásica, sino el reflejo de nuestra racionalidad en una figura ajena).

La esfera política española de 1900 no "veía" a la mujer como sujeto político de derecho, mientras que el "espectro lumínico" de la política de nuestros días sí lo hace. La posibilidad de iluminar u oscurecer ciertas zonas de lo real muestra la contingencia, la fragilidad de la distinción genérica, pero, ¿no afecta también a la sexualización de los cuerpos? ¿no es la asignación de una serie de funciones a una cierta parte del cuerpo una cualificación de lo que es, en esencia, materia "a moldear" por medio de prácticas discursivas?

Para Foucault no hay realidades naturales, pero sí hay "algo": hay contextos operacionales en los que se establecen estas realidades. Podemos hablar de "lo primero" o de "lo que inmediatamente hay", previo a la distinción sujeto-objeto: un primado de lo concreto, de la relación, de las prácticas. Las cosas sólo existen "por relación a".

La práctica es, como su nombre indica, "lo que hacen las personas". Mas estas prácticas están ocultas a la manera de la gramática de un lenguaje: somos conscientes de ella, pero su aplicación es mecánica. Creemos expresarnos naturalmente, diciendo lo que procede, pero aplicamos reglas sin tenerlas propiamente presentes. Como bien dice Veyne, "no se rompe el silencio más que para hablar un idioma determinado, ya sea el español o el latín" (Veyne, 1980: 207-8). En historia no se ha conocido otro modo de acceder a las prácticas, a esa parte oculta del iceberg político, más que por medio de los objetos, de los hechos, de las cosas que "producen" (la parte visible y, en comparación, mínima, del gélido bloque). 
La relación, por tanto, determina el objeto y sólo existe lo determinado (Ibid.: 215): el objeto no es sino una consecuencia de la práctica. Según este principio, el objeto "mujer" que la historia escrita en clave feminista clásica ha delimitado, no existía antes de esa práctica delimitadora. No existía el "blanco" femenino para la flecha lanzada a modo de reivindicación por el "arco" feminista. La existencia de la mujer a lo largo de la historia, de haberla, no se traduciría entonces por nada "efectivo". Lo que ha permitido localizar a la mujer en el campo de la historia revela su distancia originaria con cualquier objeto natural-mujer presente en una realidad transtemporal. El género que definía los límites sociales de la femineidad ha mostrado su carácter histórico, contingente y, por lo tanto innatural. Pero no sólo el género: el sexo aparece como una cualificación de cierta parte de la materia informe sobre la que la historia vierte sus miradas teóricas. Si las cosas (y estamos situados ahora en el plano fundamental de lo ente) no son más que objetivaciones de prácticas determinadas, y a la base de estas prácticas se encuentra todo un aparato teórico de comprensión de lo real (que conforma toda una ontología), lo real tiene el aspecto de una masa informe. Las formas que adquiere la materia, por ejemplo en la historia, no son más que aditamentos temporales, contingentes, a la materia eterna, primigenia y sin rostro de lo real. Por supuesto que el género es el producto de una gramática social introducida en los cuerpos por medio de siglos y siglos de represión sostenida por un vector económico-político (la necesidad de establecer alianzas entre tribus via "comercio de vientres" para evitar las guerras o la degradación de la carga genética por la endogamia). Pero es que el sexo mismo es, como diría Foucault a propósito del cuerpo, "la superficie grabada de los acontecimientos" (Foucault, 1978: 14). La sexualización del los cuerpos, la fisicidad de los mismos, la existencia de una anatomía humana tanto "de iure" como "de facto", se revela como constructo histórico. Como una mentira que ha pasado por verdad durante toda la historia. Ese "paso" ha sido comparable al de una apisonadora que ha doblegado voluntades, moldeado cuerpos, coartado libertades (definiendo la libertad posible a partir de las limitaciones de una ontología que ya incorporaba formas a la materia sin tener en cuenta la contingencia de toda forma) y, en definitiva, atentando contra "la vida" (de la materia, esa vida que es pura necesidad, pura voluntad) desde la vida cualificada (de las cosas, esa vida que, según hemos visto, es pura contingencia).

Estamos ante un universo material (primado de la materia sobre la forma), en el que la materia no tiene forma "fundamental", en la que ésta no está cualificada. Lo que informa son las prácticas, que son la instancia de actualización de esa pura potencialidad en acto que es la materia en la que consiste lo real. Es un universo de materia, pero no de cosas, no de objetos. La locura, por ejemplo, sólo existe como objeto en y por una práctica, pero esa misma práctica no es la locura. La idea de que la locura no existe es, en palabras de Veyne, "pura y simplemente positivista". Para Foucault, la materia de la locura existe realmente, pero, claro está, no como "locura". La materia es en acto, pero sin ser acto de nada (Veyne, 1980: 235). 
Foucault entiende que la perspectiva genealógica se opone a la genética, que busca el origen, la procedencia en el orden temporal (de las cosas). La genética entiende que la explicación de lo que acontece en el presente encuentra su "base" o su fundamento en un origen que ya denotaba una determinada finalidad. El origen es causa de lo actual, que es originado por aquello. Buscar un tal origen es intentar encontrar "lo que estaba ya dado", lo "aquello mismo" de una imagen exactamente adecuada a sí; es tener por adventicias todas las peripecias que han podido tener lugar, todas las trampas y todos los disfraces (Foucault, 1978: 9). Este enfoque busca el "secreto esencial" de las cosas allí donde no puede estar: en las cosas mismas. Pues esas cosas no preexisten al enfoque teórico que las alumbra.

La genealogía, por su parte, se opone al despliegue metahistórico de las significaciones ideales y de los indefinidos teleológicos. Como ya hemos dicho, se opone a la búsqueda del origen. A la empresa científica "racional": aquella que busca explicar lo existente asignándole a cada cosa su concepto, ontificando lo real, desdinamizándolo. Entiende que detrás de las cosas no se esconde su "esencia sin fechas", sino el secreto de que ellas están sin esencia, o que su esencia fue construida pieza por pieza a partir de figuras que le eran extrañas (Ibid.: 10).

El análisis genético (el de la historia tradicional, que habla de las cosas, de los objetos concretos), es una forma de saber sujeta a la gramática que lo condiciona, a la "ontología presencialista". Es el saber "oficial", por así decirlo, el que dice "algo de algo" dentro de unos límites de lo decible que nunca son límites absolutos, sino instaurados, producto de los regímenes de poder existentes. Las relaciones de poder sobre las que se asienta toda organización social o política dan lugar a formas específicas de saber, recogidas en las diferentes ramas epistémicas del gran edificio de la ciencia (del saber) de la época. Entendemos, por tanto, que ese poder que marca los límites en lo que se mueve todo saber histórico, es un poder que se ejerce, un privilegio de la instancia dominante. Esa instancia es la que extiende su particular "modo de ver" a todo el conjunto de la sociedad, a la que hace ponerse sus "anteojos teóricos", utilizar sus herramientas de habitabilidad de una realidad que es, en esencia, caos material informe.

La tendencia hegemónica y jerarquizante de los saberes propia de la empresa científica "oficial" (aquella que, con sus investigaciones y avances, va delimitando los

\footnotetext{
4 4...) una teoría es exactamente como una caja de herramientas. (...)Es preciso que sirva, que funcione.(...)Si no hay personas para utilizarla, comenzando por el teórico mismo, que deja entonces de ser teórico, es que no vale nada, o que el momento no llego aun. No se vuelve sobre una teoría, se hacen otras, hay otras por hacer. Es curioso que sea un autor que pasa por un puro intelectual, Proust, quien lo haya dicho tan claramente: tratad mi libro como un par de lentes dirigidos hacia el exterior, y bien, si no os sirven tomad otro" (Gilles Deleuze en conversación con Foucault en Foucault, 1978:79-80)
} 
límites de lo real-ontológico en una determinada sociedad) está presente de manera prácticamente inconsciente en todo acercamiento genético a lo real: siempre se analiza a partir de conceptos no problematizados, de categorías que se creen asépticas, universales y necesarias, pero que esconden siempre unos orígenes "bajos" (por históricos), establecidos desde una posición moral que valora la existencia desde caprichosas aplicaciones del par "bueno/malo".

El edificio científico de una sociedad es el producto de una economía, de una jerarquización de los saberes, y no de una inocente y desinteresada investigación sobre "la verdad en todas sus formas y a toda costa". La definición que la ciencia oficial (tomada como dispositivo disciplinario a cargo de una instancia de poder que domina los movimientos de la masa social) hace de lo que es "el saber" en la sociedad en la que opera es siempre parte de una estrategia política. El saber no ha sido hecho para comprender, ha sido hecho para hacer tajos (Ibid.: 20).

Esta actitud "cortante" de las formas de saber propias de una época (que no son sino partes del mecanismo disciplinario que obra desde el eje poder-saber) queda ilustrada de manera tremendamente gráfica en las prácticas médicas de reasignación sexual. Estas intervenciones directas, cortantes, moldean la carne y perfilan los cuerpos para hacerlos productivos desde un punto de vista económico-político. La anatomopolítica corporal queda evidenciada cuando un niño nace con un aparato sexual atrofiado o no claramente definido (lo que le da la condición de "intersexual") y es intervenido para poder hacer de él un miembro de la sociedad sexualmente binaria (cuya división por criterios anatómicos está justificada en términos de "productividad social": necesidad de reproducción para evitar la extinción o prevenir la debilidad frente a poblaciones enemigas de mayor número, posibilidad de crecimiento de la población por medio de la reproducción, capacidad de establecimiento de alianzas políticas a través de uniones matrimoniales...). Mientras el nacimiento de un ser dotado de un cuerpo inútil para los intereses productivos de la sociedad (casi ilegible a partir de la "gramática" existente) parece exigir aquí una intervención del poder-saber para darle forma a una "materia errónea", tanto para Foucault como para Butler ese nacimiento no constituirá un "error de la naturaleza". La naturaleza no comete errores porque no da a luz formas.

La intersexualidad y su amputación normalizadora nos ofrecen un caso claro de violencia sobre la materia, de ontologización del ser. Si la cultura interviene sobre lo real aplicando esquemas de inteligibilidad de la materia en términos del par materia/forma, podemos aliarnos con Nietzsche y acusar a la cultura (entendida como todo el aparato de relaciones de poder-saber que articulan los movimientos de una masa social determinada) de crear una "forma de vida" (que podría ser lo que hasta ahora hemos conocido como "vida humana") que justamente, niega la vida (de la materia, la forma de vida "original"). La delimitación de lo real en la forma de 
objetos, de entes, posibilita el "juego" de la existencia de las poblaciones de individuos humanos. Gracias a esto se puede localizar un sujeto, diferenciado del resto de objetos del discurso, y se pueden desarrollar formas de habitabilidad de la realidad por medio de instrumentos, que son concreciones, cosas, productos de teorías que intervienen sobre el plano de lo real haciéndolo cognoscitivamente productivo y que, además, hacen del caos de lo indiferenciado un mundo, un lugar habitable. Pero como ya sabemos, existe un riesgo en todo este proceso, riesgo encarnado en la figura de las formas de vida forcluídas, sometidas o directamente definidas como abyectas. La división económica de género y sexo ha posibilitado una habitabilidad del mundo a costa de la cualificación miserable de mujeres, intersexuales, homosexuales, lesbianas, hermafroditas, etc.

La genealogía tiene que dirigir su "lucha" -contra los efectos de poder de un discurso considerado científico- buscando la matriz biopolítica y disciplinaria en la pretensión de un discurso por ser ciencia y denunciando ésta como una violenta e ilegítima ambición de poder.

\section{TRAS LA CRÍTICA GENEALÓGICA, ¿HAY ALGUNA MATERIA QUE IMPORTE?}

De la mano de Foucault, Butler ha podido denunciar el origen "bajo" de las categorías de género y sexo, obrando toda una transformación sobre el rostro del mundo que conocemos. Este esfuerzo por llegar a lo incondicionado o, por lo menos, por señalar la falsedad de lo tenido por "verdaderamente ente" no sólo ha afectado a la cuestión feminista. La mujer se ha liberado de todos los condicionantes genéricos que le convertían en una especie de "actante" teatral (un personaje-tipo en el teatro del mundo, cuya peculiaridad es tan esquemática que no importa quien encarne su papel) y, también, de su propia base fisiológica: ahora la mujer no es nada más que ese papel para cuya interpretación sólo hay que reproducir el texto del género.

Al realizar toda esa "limpieza ontológica", los conceptos de "coherencia", "continuidad" o "individuo" han cobrado un nuevo significado: no son más que el material empírico de una teoría determinada. La identidad es más un ideal normativo (un dispositivo que hace visibles los cuerpos y, por extensión, los sujetos) que un aspecto descriptivo de la experiencia. En definitiva, la "coherencia" y la "continuidad" de "la persona" no son rasgos lógicos o analíticos de la calidad de la misma sino, más bien, normas de inteligibilidad socialmente instauradas y mantenidas (Butler, 2007: 71).

La identidad, que quedaba preservada por los conceptos estabilizadores de sexo, género y sexualidad, ha sido barrida del mapa ontológico a través de la 
problematización genealógica y de la presencia de "casos límite" como la transexualidad, el hermafroditismo, la intersexualidad, etc.

Pero de la misma manera que el sujeto femenino es una ficción producto de esa economía difusa que regula la sexualidad (y tiraniza todo el plano del ser), el sujeto masculino también aparece como una construcción ficticia elaborada por la ley que, entre otras cosas, prohíbe el incesto. Esta ley (denominada "ley paterna" por la tradición psicoanalítica lacaniana que tanto influye en el pensamiento de Butler), por lo tanto, es algo más que "logofalocéntrica", pues el que haya sustentado relaciones de poder en las que el hombre (portador del falo) sometía a la mujer (carente de falo) es una cuestión puramente histórica. Si admitimos los resultados del proceso genealógico, el "logo" y el "falo" de la palabra "logofalocéntrica" no quieren decir más que lo mismo. Los hombres "tienen" falo, pero nunca lo "son" más que históricamente "de hecho", pues el pene no es el equivalente a esa ley paterna, y nunca puede representarla completamente. "Ser el falo" es, en el caso del hombre, ser significado por la ley paterna, ser su objeto y su instrumento y, en términos estructuralistas, el "signo" y promesa de su poder. El falo no es más que el distintivo del logos, el centro de significación desde el que se cualifica la materia y se canaliza su "vida" por los cauces de lo ente, de lo inteligible.

El movimiento de la materia informe que constituye lo real está animado continuamente por algo que podríamos denominar deseo, pero que, por supuesto, no es deseo de nada ni nadie en particular. ${ }^{5}$. El deseo que anima la materia no tiene ni puede tener un objeto que lo colme. La malinterpretación de la naturaleza de este deseo es la que desata toda la comprensión de éste como carencia, y lo que a su vez, ata al deseo mismo a ser un movimiento de los sujetos hacia un determinado objeto (el sujeto desea aquello de lo que carece).

Todo lo que en el mundo es, no es sino materia movida por un deseo interno que no tiene finalidad alguna trascendente (esto tiene mucho sentido, ya que si absolutamente todo cae bajo el dominio de la materia sin rostro, no puede haber algo que, siendo materia, cuente con una forma que lo convierta en un perfectamente diferenciable objeto de deseo). Este es el legado de la investigación genealógica. Esta es la realidad.

El deseo es puro poder, pura voluntad gratuita, sin finalidad, envuelta en un movimiento de perpetua autoafirmación que, sin embargo, de alguna misteriosa manera produce "momentos de negación". Esos momentos son aquellos en los que se manifiesta la conciencia, el pensamiento, lo que no es mera afirmación mecánica sino

\footnotetext{
${ }^{5}$ Recordemos aquí la sentencia de Veyne: "la materia es en acto, sin ser acto de nada".
} 
que genera problematizaciones, que ofrece resistencia a ciertos sentidos del movimiento.

Este acontecer de la conciencia, posible signo de la presencia de un sujeto, tendría que ser, según lo que hemos visto, un efecto de las prácticas discursivas de las diferentes sociedades, en última instancia un discurrir de la materia informe hacia ningún lugar en particular. La conciencia humana no puede ser constituyente del mundo físico, pues ella misma, como todo lo existente, es producto de su condición de posibilidad: las prácticas históricas constituyentes. Esta "conciencia" resume de alguna manera la posición del sujeto, que contra todo pronóstico surge como un obstáculo al puro fluir de la materia desde la materia misma, sin ser otra cosa, sin poder contar con una naturaleza diferente.

Anteriormente hablamos de las estrategias de poder-saber como "violencias sobre la materia": las culturas violentaban el "pacífico movimiento de la materia" con sus formalizaciones y definiciones. Eran ataques contra la libertad dinámica de lo real que se traducían en coacciones a la libertad de ciertos "modos de ser" (mujeres, homosexuales, lesbianas, intersexuales, etc.). Pero, ¿de dónde podían provenir esos ataques más que de la materia misma? ¿cómo podíamos argumentar a favor de la inmanencia con razonamientos que evidencian la separación sujeto-objeto? ¡Si todo es materia, esa "violencia" no será sino movimiento "natural" (e incluso pacífico) de la materia! ¿qué nos permite denunciar la aplicación de esquemas de inteligibilidad de lo real por resultar violentos o injustos? ¿acaso queda algún lugar para la justicia en una realidad descualificada? ¿hay, en definitiva, algún cuerpo que importe ${ }^{6}$ ?

¿Qué hacer con la imputabilidad jurídica? ¿qué hacer con la política? Parece que del análisis foucaultiano se desprende que ambos procedimientos son derivas de la materia que, en su movimiento, hace aparecer algunas de sus obras como posibles instancias de resistencia, como herramientas de habitabilidad por institución de realidades substantes. De ser así, la justicia no sería más que un simple juego de la materia, pero que no responde a ninguna exigencia "real" de la naturaleza de la misma. Este entretenimiento precisaría, como todo juego, de unos elementos constitutivos (la sociedad, la forma tribunal, los códigos de moral,...) y toda una serie de reglas más o menos estrictas (código penal, etc.) que funcionarían como

\footnotetext{
${ }^{6}$ En esta pregunta se retoma el juego de palabras que propone el título de la obra de Butler Bodies that matter, traducida como Cuerpos que importan. La palabra matter hace referencia, en el original, tanto al verbo to matter (importar) como a la palabra materia (matter). Se juega, por tanto, con la idea de si hay alguna construcción materia-forma que realmente esconda una importancia material y no meramente condicionada históricamente. ¿Hay algún cuerpo que importe por sí mismo y en tanto que materia? ¿Hay acaso algo en la materia que compone los cuerpos humanos que dote a éstos de un estatus ontológico diferente del resto de las cosas? ¿hay en los cuerpos humanos realmente algo digno de ser singularizado y preservado?
} 
condiciones de posibilidad del "darse (con éxito)" del juego de turno. Pero en el momento en que intentamos pensar ese juego sin fin que es el movimiento deseante y lúdico de la materia, entramos en un terreno completamente nuevo. El juego jurídico, como el juego del género en las sociedades contemporáneas, no es sino un momento concreto, un escenario específico dentro de un único juego. Es un punto de aparente detención en un movimiento sin término, que en ningún punto acaba. La materia es pura voluntad, es puro poder, pero no busca nada, no necesita nada. Su movimiento, por tanto, aquel que da origen a lo múltiple y diferenciado, tiene un origen gratuito, inmanente y absurdo. Esos juegos que encontramos en el análisis histórico bajo la forma de prácticas no son más que momentos de un juego global. Pero es un juego completamente diferente a las distracciones concretas. Por ejemplo, ¿a partir de qué mediríamos el éxito de un juego tal? ¿de la diversión que produce? ¿de su verosimilitud? No parece que estas características propias de los juegos que conocemos sean aquellas a las que se pliega el juego al que juega la materia [que ni es un sujeto que pueda "querer divertirse", ni puede referirse estrictamente a otra cosa que no sea ella misma [lo que hace difícil pensar en una referencia a la realidad a la que la "ficción lúdica" ha de adecuarse]. El juego de la materia ha de ser pensado de otra manera, pues es un juego nunca visto. Se trata de un juego tan perfecto que hasta sus reglas están sometidas al azar. ${ }^{7}$

¿Cómo jugar a ese juego sin caer en el despotismo y la jerarquización de los saberes? ¿y, simplemente, cómo adoptar como base de la acción o del pensamiento la posición del sujeto, que tiene que ser una figura creada por el movimiento de la materia?

¿Fundirse en lo indiferenciado es una opción o es por el contrario la única manera de jugar con éxito? Butler y Foucault tienen que enfrentarse a este obstáculo que nace entre la genealogía y la política de los hombres, y preguntarse por el lugar de lo serio dentro del juego ideal. Pues ciertamente en sus propias investigaciones nos

${ }^{7}$ En su Lógica del sentido, Gilles Deleuze plantea una suerte de "teoría de juegos" en la que distingue dos tipos: los juegos que practicamos, nuestros juegos de azar o estrategia conocidos, y lo que él llama "el juego ideal". Los primeros son parciales por un doble motivo: porque no ocupan sino una parte de la actividad de los hombres, y porque, incluso llevados al absoluto, solamente retienen el azar en ciertos puntos (las reglas, el desarrollo mecánicos de las jugadas, etc., están fijados de antemano, como elementos no azarosos, como condiciones de posibilidad del juego). El juego ideal, el juego puro, es puro azar, y de él se pueden destacar cuatro rasgos: $1^{\circ}$ ) no hay reglas preexistentes; cada tirada inventa sus reglas, lleva en sí su propia regla; $2^{\circ}$ ) en lugar de dividir el azar en un número de tiradas-jugadas realmente distintas, el conjunto de tiradas afirma todo el azar y no deja de ramificarlo en cada jugada; $3^{\circ}$ ) las tiradas no son pues, en realidad, numéricamente distintas (son sucesivas unas respecto de otras, cualitativamente distintas, pero todas son las formas cualitativas de un solo y mismo tirar, ontológicamente uno; $4^{\circ}$ ) un juego tal, sin reglas, sin vencedores ni vencidos, sin responsabilidad, juego de la inocencia en el que la destreza y el azar ya no se distinguen, parece no tener ninguna realidad. Además, no divertiría a nadie. (Décima serie: “del juego ideal”, en Deleuze: 2005) 
encontramos con que la labor genealógica se impulsa en un cierto punto sólido (el momento inicial, el punto de partida, quizá el síntoma de lo inaceptable en la realidad conocida) en el que se apoya para volar sobre las cosas (y hacia las prácticas). ¿Desde dónde, desde qué misteriosa instancia trascendental se señalan ciertos actos (que no son más que movimientos de la materia fundamental, dinámicas carentes de todo esquema moral) como "violentos" en el sentido de injustos? ¿no parece que tanto Butler -en su denuncia de las prácticas médicas normalizadoras- como Foucault -en su denuncia de los dispositivos disciplinarios-, introducen un elemento de valoración moral absolutamente ad-hoc? ¿y no podría tratarse incluso de una concesión perfectamente consciente que oculta un acercamiento estratégico al cuerpo configurado (e incluso dotado de género) -destinado a proporcionar una libertad dentro de unos términos inviolables-, mantenida para proporcionar al sujeto la más sofisticada "libertad de la invisibilidad"?

\section{ESTRATEGIAS POST-GENEALÓGICAS \#1}

Toda la cuestión genealógica, que afectaba al completo de las cosas del mundo, reformulando el concepto de ontología que manejábamos en todos nuestros tradicionales enfoques "genetistas", no ha sido, por supuesto, un añadido tangencial al problema del feminismo. Butler, tras lograr destapar la relación de identidad que existe entre género y sexo ("una norma cultural que gobierna la materialización de los cuerpos" (Butler, 2003: 19), dice en la Introducción a Cuerpos que importan), se encuentra ante el mismo problema que hemos señalado: las positividades históricas, a la luz de la genealogía, no son las cosas, ni los cuerpos, ni los individuos,...ni ninguno de los "materiales" que pone en juego la política.

"Problematizar la materia de los cuerpos puede implicar una pérdida inicial de certeza epistemológica, pero una pérdida de certeza no es lo mismo que el nihilismo político. Por el contrario, esa pérdida bien puede indicar un cambio significativo y prometedor en el pensamiento político. Esta deslocalización de la materia puede entenderse como una manera de abrir nuevas posibilidades de hacer que los cuerpos importen de otro modo" (Ibid.: 57).

Hay que recuperar el ámbito de la política, salvándolo de las garras de ese laissez faire nihilista que propugna la absoluta libertad de movimientos de la materia y, al mismo tiempo, teniendo en cuenta todo el "viaje genealógico". El esquema ontológico-materialista de Foucault no explica a la manera de "instancia profunda" lo que sucede en el mundo de las cosas. En cierta medida ha de reconciliarnos con la ingobernabilidad del azar, pero sin apartarnos del mundo. El de la genealogía es un viaje tras el que volvemos al lugar de partida pero sin ser los mismos. Así, se entiende que esta parte de su obra (la desarrollada a mitad de los años 70 a la manera de una "microfísica del poder") pueda ser una especie de propedéutica para el trabajo del 
carácter o del estilo esbozado durante los años 80. Un nuevo trato "técnico" con lo superficial se busca a partir de un principio no moral: el principio del placer. Se intentará entender el deseo de la materia a través del placer de los sujetos. Y para ello será necesario volver del ámbito microfísico al fisico: se buscan en el mundo, entre las cosas, las brechas por las que se pueda deslizar cierta comprensión del juego ideal "como tal".

Con toda seguridad sabemos que el juego ideal no puede ser realizado por un hombre. Sólo puede ser pensado, y además, como señala Deleuze, pensado como sin sentido. Afirmar todo el azar, hacer del azar un objeto de afirmación, sólo el pensamiento puede hacerlo. Se trata, pues, de un juego reservado al pensamiento y al arte (actividades gratuitas en el sentido de "sin finalidad": con términos o etapas, pero sin punto de acabamiento), donde ya no hay sino victorias para los que han sabido jugar, es decir, afirmar y ramificar el azar, en lugar de dividirlo para dominarlo, para apostar, para ganar. Este juego que sólo está en el pensamiento, y que no tiene otro resultado que la obra de arte, es también lo que hace que el pensamiento y el arte sean reales y trastornen la realidad, la moralidad y la economía del mundo (Deleuze, 2005: 91).

El juego ideal nos queda vedado, y el terreno abierto por la genealogía, inasible desde sus propios términos, políticamente yermo. Ha de proponerse un acercamiento estratégico a la comprensión de "lo absolutamente no estratégico": el azar que anima la materia, el juego puro. Toda comprensión de este plano de lo ininteligible precisará, entonces, de un planteamiento de base crítica: hay que delimitar el espacio del juego estratégico, sus reglas y sus actores, para recuperar cierta noción de lo político capaz de animar una acción acompasada con los caóticos movimientos de la realidad. Lo político se comprenderá entonces como prácticas o juegos estratégicos en libertad, juegos entre partenaires capaces de actuar libremente y no meras marionetas de un poder fundamental. El poder es indiscernible de las prácticas, aparece al mismo tiempo que estas, como el halo que envuelve ese efecto de superficie. El postulado de la esencialidad de la materia frente a la historicidad de las formas no es del todo riguroso. Es a través de la arqueología que, ante el trato con objetos (materia y forma) a lo largo de su evolución histórica, extraemos la conclusión de que no hay objetos como tales, sino efectos del discurso, de las prácticas formalizadoras. Pero el hecho de que podamos pensar que "otro mundo es posible" al observar que las formas son contingentes no nos permite postular una materia sin forma, pues esto es algo que, en rigor, no conocemos en absoluto. La teoría performativa del poder que subyace a todo este planteamiento foucaultiano, pierde de vista que no hay poder sino encarnado en los objetos del discurso. El poder "a secas", como potencia en acto, no se ofrece más que como un "resto" en las cosas. Sabemos que la potencia de la realidad supera a su estado de actualización presente (sabemos, por ejemplo, que una bio-mujer puede desentenderse de las tareas del 
hogar aunque de hecho no lo haga), pero una realidad de pura potencia en acto entendida como materia informe es, no sólo inhabitable, sino impensable.

Es a partir de aquí que Butler va a desplegar cierta visión de la política genérica ligada a un poder performativo encarnado en los cuerpos que, continuamente, violan los términos del discurso en el que voluntariamente se inscriben. La llamada "parodia de género" será uno de estos juegos estratégicos que actuará como un caballo de Troya, mostrando la flexibilidad de la realidad encarnada en cuerpos progresivamente "limpios" de naturaleza esencial, hasta llegar a un punto en el que la importancia de los cuerpos sea la importancia misma de la materia expresada en un estilo (como el efecto puramente superficial de la labor de construcción de sí efectuada por el conjunto de la realidad: tomada como sujeto y como objeto). Se tiene en cuenta, por tanto, que la materia es en acto (de facto), pero sin ser acto de nada (sin ser propiedad de ciertas formalizaciones que constituyen los cuerpos que, de iure, importan). La práctica paródica es un interesante puente de camino a esos supuestos cuerpos que por mor de su "esencial" materialidad-importan ${ }^{8}$.

Hacia el final de El género en disputa, Judith Butler repara en cómo dentro de las parejas formadas por individuos del mismo sexo existe una marcada tendencia a la reproducción de los clásicos papeles genéricos de hombre y mujer. Entre las lesbianas en particular, existe todo un "movimiento" de codificación de los miembros de la pareja desde un perverso binarismo. Por un lado están las llamadas butch, bio-mujeres que asumen cierto rol masculino dentro de la pareja a través de la vestimenta, la actitud, y, en general, todos aquellos rasgos que solemos concebir ligados al "estilo masculino". En el otro lado se encuentran las femmes, que juegan el papel más marcadamente femenino (entendido desde un punto de vista genérico: cierta actitud históricamente ligada al género femenino y a los cuerpos de las mujeres). Estos dos "personajes" juegan al juego del género desde una cierta dislocación de las identidades que, de inicio, pone en entredicho la normalidad sexo-género. Pero hemos de llegar a ver este "juego" de identidades no como una simple imitación o burla de los cánones masculino y femenino (¿cómo se puede vivir haciendo una perpetua broma? ¿es posible hacerlo sin caer en el más despreciable de los cinismos?), sino como una producción que se presenta (en su efecto) como una mera imitación.

En este punto se podría argüir que, según este razonamiento, la separación genérica entre hombre y mujer anteriormente denunciada por sus orígenes históricoeconómicos, se está en cierta forma naturalizando: si los miembros de la pareja de lesbianas producen inconscientemente (no meramente reproducen) la dualidad genérica, ¿no hay entonces escapatoria a este juego de identidades?

\footnotetext{
${ }^{8}$ Se hace patente de nuevo la dificultad de poner en nuestro idioma el ingenioso matiz terminológico con el que juega la frase "bodies that matter".
} 
Conviene llamar la atención en este momento sobre el tercero de los "puntos cardinales" señalados al comienzo del ensayo: la sexualidad. Foucault entiende la sexualidad como una organización históricamente concreta de poder, discurso, cuerpos y afectividad. La sexualidad genera el "sexo" como un concepto artificial que de hecho amplía y disimula las relaciones de poder que son responsables de su génesis (Butler, 2007: 194). Al descubrirse que no hay cuerpo más allá de la ley que lo forma, la sexualidad se ve afectada y ha de redefinirse como algo que existe ya "antes de la ley", como multiplicidad libidinal que quiere liberarse de las cadenas del sexo. Esta liberación, de ser posible, se efectuará dentro de los términos de la ley, produciendo paradojas o contradicciones de la misma que darán como resultado una suerte de emancipación del cuerpo culturalmente construido, no hacia un pasado "natural", sino hacia un futuro "no escrito" y lleno de posibilidades (Ibid.: 196).

Si la sexualidad genera el sexo, y el sexo es una construcción genérica, nos encontramos con que a la base de toda la organización económica de lo social, e incluso de toda la organización ontológica de lo real, se encuentra esa multiplicidad libidinal que, anteriormente bautizamos con el nombre de deseo. La realidad es producto de una voluntad que es puro deseo, y el papel de la política ha de ser el de procurar una continuidad entre deseo de la materia y placer de los entes.

Este placer se alcanzará, por ejemplo, mediante el uso del cuerpo sexuado, pero teniendo en cuenta que el sexo es un constructor que define y, por tanto, limita las posibilidades de la materia. En este sentido, la maximización del placer pasará por la des-sexualización del cuerpo (en el sentido de una desorganización, de una supresión de finalidades constitutivas de lo hylemórfico que ha de tomarse como una descontextualización y recontextualización continua de todo lo que se considera "organizado en función de ciertos fines" [como, por ejemplo, ciertas zonas del cuerpo destinadas a la reproducción o clasificadas como "erógenas" frente al resto]). Esta operación de desterritorialización (en términos de Deleuze) realizada en el ámbito de lo físico, contribuye a romper las fronteras formales que han venido definiendo las "jurisdicciones" de cada ente. Se trata de un práctica de desujección (el "sujeto" va desprendiéndose de la tradicional localización corpórea, que no era más que "la superficie grabada de los acontecimientos" (Ibid.: 255)) que es, al mismo tiempo, la de una construcción de sí no sostenida en lo que Foucault llamaría "el régimen de la verdad".

El juego de las identidades que la pareja butch/femme parece reproducir sin remedio, puede ser sin embargo un juego con las identidades, dentro del cual desarrollar una virtud. Nos separamos, por tanto, de toda consideración moral del concepto de virtud, y, situados en una ética de la performatividad, intentaremos desarrollar esta complicada idea (virtud sin modelo, virtud no moral). 
La virtud consiste, aquí, en algo así como una relación crítica con las normas que rigen esos discursos que la acción de la pareja de lesbianas pervierte (sin voluntad de pervertir, sin un principio reactivo sino absolutamente activo $\mathrm{y}$, en ese sentido, totalmente acompasado con "el deseo de la materia"). Como si de un baile se tratase, la pareja entra en una relación virtuosa con la música de la materia, de tal manera que es capaz de imprimirle cierto "alma" (lo que en terminología musical se denominaría swing, y que es una aportación del músico o del bailarín absolutamente irreductible a la técnica. Uno no aprende a interpretar con swing: lamentablemente, es algo que ha de producirse como un efecto de superficie desde cierto uso de los elementos técnicos (que sí se aprenden)) ${ }^{9}$ a la mera citacionalidad de los "pasos" del baile de turno. La virtud toma entonces la forma de una estilización específica (cuyo resultado o efecto será la subjetividad) realizada a partir de las reglas, pero no reductible a la mera aplicación de las mismas.

Con su uso personal de las normas, butch y femme comienzan imitando los originales masculino y femenino, pero terminan produciendo una perversión que desplaza el significado del original mismo. Como dice Butler, el concepto de una identidad de género original o primaria es objeto de parodia dentro de las prácticas culturales de las travestidas, el travestismo y la estilización sexual de las identidades butch/femme (Ibid.: 268). Pero es ésta una parodia no satírica, irreductible a una burla. Como ya se ha señalado antes, esta producción de diferencia o de "resto" que señalaba el acontecer de cierta virtud ético-estética, no tiene un impulso reactivo a su base. Se trata de una producción puramente "inocente" que aparenta ser la imitación de un modelo genérico tenido por original pero que, más allá, imita el mito de la originalidad en sí.

\section{ESTRATEGIAS POST-GENEALÓGICAS \#2}

La reflexión de Deleuze que delimitaba el "campo de acción" del juego ideal desde la subjetividad en los terrenos del pensamiento y el arte, establece puentes con la última etapa del pensamiento de Michel Foucault, para quien la acción política post-genealógica había de partir de una nueva noción de "sujeto". Foucault hablará de procesos de subjetivación en el sentido de "creación de modos de existencia", y en ningún caso en el de "constitución de un sujeto". No hay sujeto, hay producción de

\footnotetext{
${ }^{9}$ Un ejemplo para ilustrar esta metáfora musical: la primera canción en contener el término "swing" en su letra fue el standard It don't mean a thing (if it ain't got that swing), de 1931, con música de Duke Ellington y una letra escrita por Irving Mills, en la que se cantaba: "What good is melody?/ what good is music?/ if it ain't possessing something sweet/It ain't the melody/ it ain't the music/ there's something else that makes this song complete". Evidentemente, ese "resto", ese "algo más" o esa "otra cosa" que no es ni la melodía ni la música (something else), es el swing al que hemos hecho referencia.
} 
subjetividad, y precisamente por esta ausencia de sujeto fundante, la subjetividad tendrá que ser producida en cada momento. ${ }^{10}$ Pero, ¿por quién o qué? Se supone que por la inercia misma o el desarrollo del juego ideal de la materia, esto es, por ese eje del poder que a su vez produce el "saber". Mas, como se ha visto en la precedente metáfora musical, la subjetividad se manifiesta bajo la frágil figura del estilo, irreductible a toda forma de "saber" (saber técnico, "saber citar la ley") o de "poder" susceptible de ser ejercido. Por tanto, hemos de buscar la producción de la subjetividad en un cruce entre el eje de ese poder que es puro deseo o pura voluntad afirmativa, y el misterioso eje ético que nace en este mismo terreno de lo indiferenciado y que, sin embargo, introduce diferencias, pertinencias, virtud.

Hay entonces un cierto arte de la construcción de sí que, lejos de encontrar sus leyes o caracteres específicos en un corpus preexistente, produce la regla en cada momento que se "juega". Este arte se manifiesta en el frágil acontecer del estilo, que llama la atención sobre cierta actitud o ethos "subyacente" que templa el carácter del sujeto ante la realidad mundana, y le permite captar algo eterno ${ }^{11}$ que no está ni más allá ni detrás del momento presente (de las cosas), sino en él mismo.

${ }^{10}$ Hay que reparar aquí en la naturaleza performativa de la acción dentro de lo que hemos llamado "juego ideal" (y todo juego no es, en última instancia, sino una modalización incompleta de este "juego puro") y que no es otra cosa que el absurdo movimiento de la materia que da lugar a todo lo real.

La performatividad ha de entenderse, no como un "acto" singular y deliberado, sino, antes bien, como la práctica reiterativa y referencial mediante la cual el discurso produce los efectos que nombra. El poder que constituye el plano ontológico con su movimiento es performativo: crea realidad y se torna su "justificación". Pero como el dinamismo de la materia no tiene ningún sentido definido, partir desde la realidad de los objetos hacia su instancia creadora (de las formas a la materia) en busca de una "razón de ser", es buscar "derecho" donde no hay más que "hecho". No hay justificación más allá del mero poder. (En cualquier caso, esto ya se extrajo del descubrimiento de la raíz histórico-económica de las supuestas naturalezas o esencias de lo real).

Es en el ámbito de los juegos conocidos, que operan con "cosas", con cuerpos y con objetos, donde podemos señalar cierta "instancia responsable" a la que pedir justificación por la acción (por entender que se trata de $s u$ acción).

${ }^{11}$ Llamo la atención sobre ésta "experiencia de lo eterno" por tratarse de un signo de "vivencia" del juego ideal. Lo que no tiene lugar en el mundo de las cosas es aquello que no se presta a la ontologización en términos espacio-temporales: la eternidad no es propia de los juegos corrientes, que empiezan y acaban, que ponen en juego elementos concretos y localizables. La experiencia de lo eterno no es la experiencia sensible, pero es posibilitada por las cosas. Si pensamos en lo que se suele llamar "experiencia estética" podremos entender mejor esta cuestión. La experiencia estética precisa de un sujeto perceptor y de un objeto percibido por la sensibilidad del primero. Este esquema, compartido con el del conocimiento empírico es, sin embargo distinto de aquel porque proporciona una experiencia no ya del objeto percibido ("conocido") sino de algo no sensible que, sin embargo, comparece en el objeto (o más bien en el espacio intermedio que une/separa sujeto y objeto). La experiencia de la cosa tomada estrictamente desde sus características sensibles es la de un objeto, la de una cosa, una sensación delimitada a unas coordenadas espacio-temporales concretas. Pero la experiencia estética se tiene "a la vez", como un suplemento de la cosa. Mientras la cosa es delimitable cronológicamente, lo que ha sucedido entre la cosa y el sujeto no es propiamente mensurable. Escapa a todo cálculo de la misma manera que un enamorado no es capaz de concretar la "cantidad de amor" que le profesa a su "objeto de 
"La ontología crítica de nosotros mismos (genealógica en su finalidad y arqueológica en su metodología) no debe ser entendida ni como una teoría ni como una doctrina, ni tampoco como un corpus de saber constante y acumulativo; debe ser entendida como una actitud, un ethos (...)" (Foucault, 1983: 25)

El género será entendido como un estilo corporal, como un proyecto sostenido sobre repeticiones, como una estrategia (es un acto a la vez intencional y performativo). Pero el del género no es un estilo derivado de un acto o actos "expresivos": no hay instancia profunda de significado ni núcleo identitario del sujeto. Si los atributos y los actos de género, o sea, las diversas maneras en que un cuerpo muestra o produce su significación cultural, son performativos, entonces no hay identidad preexistente que pueda ser la vara de medición de un acto o atributo; no hay actos de género que sean verdaderos o falsos, reales o distorsionados, y el postulado de una verdadera identidad de género se revela como una ficción regulativa. Que la realidad de género esté creada por performances (actuaciones teatrales) sociales sostenidas significa que las ideas mismas de un sexo esencial, una verdadera o constante masculinidad o feminidad, están también constituidas como parte de una estrategia por la cual el aspecto performativo del género queda encubierto (Butler, 1990: 270-282). Pero, ¿cuál es el agente de la acción performativa de construcción genérica? Butler señala que si el género es algo construido, no lo es necesariamente por un "yo" o un "nosotros" que existan antes de la construcción (en ningún sentido espacial o temporal del término "antes"). Afirma que, sujeto al género, pero subjetivado por el mismo, el "yo" sólo emerge dentro (y como la matriz de) las relaciones de género mismas (Butler, 2003: 25). El sujeto es producido dentro de una matriz -y como una matriz- genérica de relaciones, por lo tanto, toda posibilidad de acción queda reducida a una práctica reiterativa o rearticuladora, inmanente al poder y no considerable como una relación de oposición externa al mismo. Nada queda fuera del eje del poder, y toda resistencia habrá de articularse "citacionalmente", esto es, dentro de los términos de los juegos conocidos.

La performatividad del género no será entonces un voluntarismo irrestricto: de hecho, esta performatividad es imposible de concebir al margen de tales restricciones

deseo". Así como el enamorado no puede expresar sino confusa e insatisfactoriamente su amor por la aquello que ama, el sujeto "herido" por la experiencia estética ante o con la cosa, no puede "dar razón de lo que ha sucedido" sin caer en vaguedades e indeterminaciones. Pero esta incapacidad, como decimos, no es fruto de una incomprensión de lo sucedido: lo que ha pasado es, en rigor, incomunicable, imposible de traducir en términos concretos. De la absoluta imposibilidad de asignar a la experiencia estética un objeto del que es "signo" se puede extraer que su régimen de existencia no es el propio de los objetos concretos (determinables cronológicamente), sino el de aquello que no tiene forma propia (aunque la suya sea una materia que precise de ciertas formalizaciones para ser experimentada: pensemos en la capacidad de evocación estética de ciertas obras de arte, o en la de determinadas situaciones, o incluso en la de ciertos objetos "profanos") y que, por lo tanto, existe eternamente, como un borroso concepto, habitando ciertos objetos concretos cada vez. 
políticas registradas "psíquicamente". La posibilidad de construirse por medio de las prácticas, al margen de toda regla codificadora previa, es cuestionada por Butler. Constructivismo no es voluntarismo, ni libre juego, ni artificio de un sujeto que es libre para formar su sexualidad según le plazca. Por el contrario, se sostiene que la dimensión performativa de la construcción es precisamente la repetición forzada de normas, o sea, que la restricción es la condición misma de la performatividad (Ibid.:144-5). Resulta curioso que sea precisamente desde la apelación a la norma desde donde vaya a emerger la "resistencia" a la coerción. Ya planteamos en páginas anteriores la "injustificada apelación a la justicia" subyacente a los desarrollos teóricos de Butler y Foucault, y el problema de la "instancia de denuncia" parece seguir en pie.

\section{CONCLUSIÓN}

Podemos decir, con Butler, que la resistencia consiste en la "estilización de sí en los límites del ser establecido" ", y nos haríamos cargo de toda la polémica restricción a la acción preformativa que constituye su necesaria estructura citacional. Si no hay otra resistencia posible que la que se da desde dentro de los límites del ser establecido (y si admitimos definitivamente que no hay subjetividad fuera de un cierto espacio ontológico de juegos estratégicos), hemos de volver la mirada hacia la estrategia paródica, que se presenta como la opción de desubjetivación de mayor potencia política revolucionaria.

¿Qué establece una repetición subversiva dentro de las prácticas significantes de género? (Butler, 2007: 283), se pregunta Butler llegando al final de El género en disputa, y ante la más que fundada sospecha de que la mera exposición de la condición naturalizada de la heterosexualidad no basta para subvertirla. Ante esta cuasi-evidencia (corroborada cientos de veces por la impotencia subversiva de las referencias satíricas: por mucho que creamos en la mordacidad de los humoristas gráficos que publican en los diarios, su tendencia a hacer humor a partir de la "cita al político" que busca la sonrisa por la mera exageración o descontextualización de sus declaraciones, funciona las más de las veces como un refuerzo de aquello que citaba burlescamente, como un factor de familiarización o naturalización de lo satirizado), se impone la necesidad de distinguir dos tipos de repetición en función de su capacidad subversiva. Por un lado estaría la simple copia y por otro el simulacro. ${ }^{13}$ La copia opera remitiéndose al original y ofreciendo una imagen de este apoyada en la semejanza. Es -como dice Deleuze en Lógica del sentido- un pretendiente "bien

\footnotetext{
${ }^{12}$ BUTLER, J., “¿Qué es la crítica? Un ensayo sobre la virtud de Foucault” (VV.AA, 2008: 159)

${ }^{13}$ Este desarrollo de los conceptos de copia y simulacro se apoya, fundamentalmente, en el primer apéndice a Lógica del sentido, titulado "Platón y el simulacro".
} 
fundado" al favor del original, que toma la forma de un icono imitador. Se trata, en definitiva, de una buena copia, semejante al original-modelo. El simulacro, por su parte, aparece como una imagen carente de semejanza, que no se parece a la cosa que imita y que, por lo tanto, no merece ocupar su lugar icónicamente, pues ni siquiera es capaz de "citar" a la autoridad de manera estricta. Los simulacros poseen una perversión y una desviación esenciales, que remiten a una cierta producción de diferencia en la que caen cada vez que remiten al original. Son malas copias, incapaces de colmar la más mínima pretensión de semejanza. Cada vez que citan, tienden a subvertir lo citado, deviniendo "suplementos": elementos que suplen a un original y que, al mismo tiempo, añaden una nota suplementaria, adicional, en esa sustitución. La operación del simulacro es doblemente suplementaria: usurpa un lugar ajeno, y lo hace "como otro", como un suplente no semejante al original.

Contestaremos, por lo tanto, que lo que hace subversiva a una repetición dentro de cualquier práctica significante (incluida la de género) es su naturaleza suplementaria o diferencial, su condición de simulacro del original y no de mera copia. La parodia de género, el pastiche, es, frente a la copia satírica, una mala copia, un simulacro.

¿Pero no nos mostró la investigación genealógica la naturaleza no-natural o no esencial de los principios de semejanza y de identidad (por remitir a cosas, a objetos, en un ámbito en el que éstos no eran sino productos de las prácticas discursivas? ¿no convierte esto toda copia en una copia esencialmente mala? Parece que el simulacro no es simplemente algo así como una "copia degradada", sino que es aquella cita que, positivamente, activamente, niega tanto el original como la copia para "instaurar" un régimen de perpetua producción de diferencia. Es cierto que -por ejemplo, en el caso del juego de identidades butch/femme- cierta semejanza y cierta identidad persisten, pero lo hacen como efectos de la producción de diferencia en que consiste la repetición subversiva. Hay una risa subversiva en el efecto de pastiche de las prácticas paródicas, en las que lo original, lo auténtico y lo real también están constituidos como efectos (Ibid.: 284).

Esta risa es la puesta en duda de un régimen epistemológico/ontológico, una carcajada, provocada en plena práctica de construcción de sí, que actúa como el hilo que une el deseo de la materia y el placer del sujeto. El sujeto es, entonces, la línea de estilo que traza el conjunto de las prácticas que lo ven "manifestarse", y lo serio se manifiesta, curiosamente, en la parodia, por ser el procedimiento estratégico que pone -en la medida de lo posible- en continuo los espacios de la destreza y del azar, de los "juegos estratégicos en libertad" y del "juego ideal". El trabajo del placer por medio de la apropiación paródica de los discursos existentes será el más riguroso de todos los planteamientos críticos, aquel que "intenta, tan amplia y extensamente como sea posible, dar un nuevo impulso al indeterminado trabajo de la libertad" (Foucault, 
1983: 22) desde una misteriosa instancia trascendental de carácter ético-estético perfectamente acompasada con el devenir de lo real.

\section{BIBLIOGRAFÍA}

BUTLER, Judith (1990): Actos performativos y constitución del género: un ensayo sobre fenomenología y teoría feminista originalmente en Case, S-E. (ed.): Performing Feminisms: Feminist Critical Theory and Theatre, Baltimore, John Hopkins University Press p.270-282.

BUTLER, Judith (2003): Cuerpos que importan. Buenos Aires, Paidós

BUTLER, Judith (2007): El género en disputa. Barcelona, Paidós

DELEUZE, Gilles (2005): Lógica del sentido, Barcelona, Paidós

DÍAZ MARSÁ, Marco (1996): Acerca de la formación regular de objetos del discurso en la Arqueología de M. Foucault. Anábasis. Revista de filosofia, no 4 (1996/1), pp. 129146

FOUCAULT, Michel (1978): Microfisica del Poder, Madrid, La Piqueta

FOUCAULT, Michel (1983): Was ist Aufklärung?. Anábasis. Revista de filosofía, nº4 (1996/1), pp. 9-26

VEYNE, Paul (1990): Cómo se escribe la historia. Ensayo de epistemología, Madrid, Alianza Editorial

VV.AA. (2008): Producción cultural y prácticas instituyentes. Líneas de ruptura en la crítica institucional, Madrid, Traficantes de Sueños 